\title{
Shrub island effects on a high-altitude forest cutover in the eastern Tibetan Plateau
}

\author{
Yechun Wang • Weikai Bao • Ning Wu
}

Received: 17 December 2010 /Accepted: 10 March 2011 /Published online: 2 September 2011

(C) INRA and Springer Science+Business Media B.V. 2011

\begin{abstract}
- Context The roles of woody-plant islands are well documented in low-altitude regions, but research related to such shrub effects in high-altitude regions is scant.

- Aims Four common shrub species (Cerasus trichostoma, Ribes glaciale, Rosa omeiensis and Salix sphaeronymphe) in a high-altitude forest cutover of the eastern Tibetan Plateau, were chosen to evaluate the effects of both species and size of shrub islands on microhabitats, herbaceous communities and woody seedling regeneration.

- Methods Total 86 shrubs with different sizes were investigated; The shrub size, herb community structure and species composition, litter, soil nutrient and microclimate parameters beneath the shrub canopies were also measured.

- Results All shrubs significantly ameliorated microclimates, increased content of soil organic matter and total nitrogen, both grass and forb species richness, and litter cover and biomass, and promoted woody seedling recruitment (richness and number), but decreased cover and biomass of the herbaceous community beneath them. These effects were greater for larger shrubs, and also varied among shrub species with different crown architectures. We also found differences in species-dependency of the shrub effect for the responses of the herbaceous and woody
\end{abstract}

\section{Handling Editor: Gilbert Aussenac}

Y. Wang $\cdot$ W. Bao $(\triangle) \cdot$ N. Wu

Key Laboratory of Ecological Restoration,

Chengdu Institute of Biology, Chinese Academy of Sciences,

No. 9, Section 4, Renming South Ave, P.O. Box 416, Chengdu,

Sichuan 610041, People's Republic of China

e-mail: baowk@cib.ac.cn

Y. Wang

Graduate School of the Chinese Academy of Sciences,

Beijing 100039, People's Republic of China seedling species, suggesting that shrubs also indirectly facilitate forbs and seedling regeneration through competition release of grasses. We conclude that shrub-island effects are size- and species-dependent. In order to accelerate natural succession and restoration in alpine cutovers, shrub island preservation and their effective utilization as reforestation microhabitats should be integrated into vegetation management procedures.

Keywords Shrub island effect. Alpine cutover- Tibetan Plateau $\cdot$ Herbaceous community. Progressive succession

\section{Introduction}

Shrub-island effects are widely recognized in many ecosystems (Maestre and Cortina 2005; Duarte et al. 2006; Endo et al. 2008), and can generally be grouped into two categories. One is the microhabitat effect, which includes mainly microclimate amelioration (Franco and Nobel 1989; Endo et al. 2008) and soil nutrient enrichment (Garner and Steinberger 1989; Throop and Archer 2008). The other is the nucleation succession effect, which involves mainly the replacement of herbaceous species and the acceleration of woody seedling regeneration (Pugnaire et al. 1996; Duarte et al. 2006). Cuesta et al. (2010) found that the shrub Retama sphaerocarpa not only directly facilitated late-successional Quercus ilex seedlings by reducing seedling photoinhibition and water stress, but also improved seedling growth indirectly by reducing the competitive capacity of herbs. In most cases, these two kinds of shrub-island effects (including direct and indirect effects) occur simultaneously and are equally important, especially for ecosystems in stressed environ- 
ments (Brooker et al. 2008). Indeed, shrub-island effects are managed by a complicated interaction among biotic and environmental factors, with direct and indirect, and positive and negative interaction mechanisms, and vary across spatial and temporal scales (Levine 1999; ReismanBerman 2007; Brooker et al. 2008). Therefore, a better understanding of shrub island effects across spatiotemporal scales will provide an important pathway towards understanding plant-environment interaction mechanisms.

Shrubs with different size and crown architectures differ in how they affect the microhabitat $(\mathrm{Li}$ et al. 2007; Throop and Archer 2008). These differences may lead to the formation of different assemblages of herbaceous and woody plant establishment beneath the shrub, which will affect patterns of nucleation succession, involving mainly the replacement of herbaceous species and the acceleration of woody community regeneration (Pugnaire et al. 1996; Duarte et al. 2006; Endo et al. 2008). In addition, different plant species, such as grasses and forbs, may be affected differently by shrub islands; forbs usually exhibit morphological, life historical and ecophysiological characteristics that contrast sharply with those of grasses, e.g., their intrinsically higher photosynthetic capacity and resource-use efficiency compared to grasses (Turner and Knapp 1996). They can therefore, be expected to react differently to shrubs if shrubs affect light intensity and soil nutrient levels. Alpine plants have shorter growth periods, and have to endure higher radiation and lower temperatures when compared with low elevation regions. Thus, alpine plants face more rigorous challenges and experience different growth processes, and have developed various adaptation strategies to cope with those environmental restrictions (Körner 2003; Dona and Galen 2007). Investigating the roles of alpine shrub islands would help our understanding of the mutual interaction of plants and vegetation dynamics in the unique alpine environment.

The roles of woody-plant islands in forest restoration have been well documented in low-altitude regions (Mattson and Putz 2008). However, relevant research in high-altitude destroyed regions is scant (Dona and Galen 2007), and the relationships between species, island size and their effects in these habitats are not well understood.

Alpine cutovers are found extensively on the eastern Tibetan Plateau, as a consequence of excessive logging alpine forests near the timberline (3,400-3,900 ma.s.1.) (Wang et al. 1995). Currently, most recent cutovers ( $<25$ years) remain in the early succession stage, still covered by herbaceous communities with scattered shrubs (Bao 2004). Although traditional reforestation has been carried out after clear felling for the past 30 years, most such efforts have not succeeded, due mainly to the harsh climate, environmental degradation and yak grazing (Wang et al. 1995; Bao 2004). Developing ways to effectively promote restoration of alpine cutovers has been being a pressing problem related to the establishment of regional ecological safety barriers. Previous work in the alpine region has found that cultivating spruce seedlings beside tall shrubs can allow better survival and growth, implying that microhabitat improvement by shrubs is probably one of the mechanisms responsible for this (Wang et al. 1995; Bao 2004), but this has not yet been tested. It is well known that vegetation succession on cutovers after forest logging proceeds from herbs to shrubs and finally to the forest stage, and that shrubs provide a key link from herbs to the woody stage, but there is little information on succession mechanisms relating to the role of shrubs on alpine clear-cut areas.

In the present study, therefore, we chose four common shrub species to evaluate the effects of shrub size and species on a high-altitude cutover in the eastern Tibetan Plateau. The following questions were addressed. (1) How do shrubs affect microhabitats in the high-altitude cutover? (2) How do shrub islands affect the herbaceous community in the understorey, especially grasses and forbs? (3) How do shrub islands affect natural recruitment of woody seedlings? (4) How do these effects vary with shrub size and species?

\section{Methods}

\subsection{Study site}

The study area is located in Rangtang County, northwest Sichuan Province, China $\left(32^{\circ} 19^{\prime} \mathrm{N}, 100^{\circ} 48^{\prime} \mathrm{E}\right)$. It is a typical high-altitude forest-grassland ecotone of the eastern Tibetan Plateau. It lies in a plateau monsoon climate area with an annual average temperature of $4{ }^{\circ} \mathrm{C}$ and an annual average rainfall of $700-800 \mathrm{~mm}$. The growing season for vascular plants is about 90-105 days per year, from late May to early September (Wang et al. 1995). The main vegetation types in the region are primary spruce forests, alpine scrublands and meadows. Large-scale harvesting of the original forests occurred from 1976 to 1998, and left a sequence of cutovers of an average size of about 5 ha. Most cutovers are dominated by herbaceous communities with sparse shrubs. Our study was undertaken on an 18-year-old cutover (area: $5.3 \mathrm{ha}$;

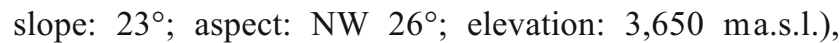
where herbs and shrubs account for about 85 and $15 \%$ of total cover, respectively. 


\subsection{Focal shrub species}

Four deciduous shrub species, Cerasus trichostoma, Ribes glaciale, Rosa omeiensis and Salix sphaeronymphe (hereafter referred to as Cerasus, Ribes, Rosa and Salix, respectively), were selected because they are common on the high-altitude cutovers, and have different crown architecture and fruit type: Ribes (low-branching, fleshy fruits), Cerasus and Rosa (medium-branching, fleshy fruits), and Salix (high-branching, dry fruits). In August 2008, Cerasus, Ribes, Rosa and Salix of different sizes were chosen and the corresponding area, age and height were investigated in the field (Table 1). Crown cover was estimated from crown projection diameter as the shrub area. The distance from the ground to the mean height of most sprout stems were determined by tape measure as the shrub height. The age of the shrub was determined by counting the growth rings of the thickest branch.

\subsection{Microclimate measurements}

To investigate the microclimate effect of shrub size and species, we chose 48 additional shrubs randomly, and then classified them into three classes according to area size: small $\left(0.5-1.0 \mathrm{~m}^{2}\right)$ medium $\left(2.0-3.0 \mathrm{~m}^{2}\right)$ and large $\left(5.0-7.0 \mathrm{~m}^{2}\right)$ shrubs, with four shrubs for each of the three classes. Light intensity, air temperature and relative humidity at $5 \mathrm{~cm}$ above the ground on the down-slope

Table 1 Basic characteristics of Cerasus (C. trichostoma), Ribes ( $R$. glaciale), Rosa ( $R$. omeiensis) and Salix (S. sphaeronymphe) sampled on a high-altitude cutover, eastern Tibetan Plateau

\begin{tabular}{lllll}
\hline Species & & Area $\left(\mathrm{m}^{2}\right)$ & Age (years) & Height $(\mathrm{cm})$ \\
\hline Cerasus & $n$ & 22 & 22 & 22 \\
& Minimum & 0.57 & 8 & 133.32 \\
& Maximum & 11.10 & 19 & 375.80 \\
& Mean $\pm \mathrm{SE}$ & $3.51 \pm 0.52$ & $12.23 \pm 0.54$ & $246.89 \pm 12.33$ \\
Ribes & $n$ & 23 & 23 & 23 \\
& Minimum & 0.56 & 7 & 124.82 \\
& Maximum & 7.32 & 20 & 228.36 \\
& Mean $\pm \mathrm{SE}$ & $2.36 \pm 0.32$ & $12.91 \pm 0.73$ & $185.37 \pm 6.80$ \\
Rosa & $n$ & 21 & 21 & 21 \\
& Minimum & 0.52 & 5 & 119.00 \\
& Maximum & 9.94 & 20 & 290.27 \\
Salix & Mean $\pm \mathrm{SE}$ & $3.05 \pm 0.52$ & $11.05 \pm 0.88$ & $202.95 \pm 10.43$ \\
& $n$ & 20 & 20 & 20 \\
& Minimum & 0.61 & 7 & 140.71 \\
& Maximum & 12.35 & 21 & 495.62 \\
& Mean $\pm \mathrm{SE}$ & $4.64 \pm 0.93$ & $12.79 \pm 0.86$ & $295.50 \pm 20.11$ \\
\hline
\end{tabular}

middle position of the shrub canopy were measured from 12:00-14:00 pm on two sunny days (17-18 August 2008). We presumed that the selected summer sunny days at noon could represent the common typical situation beneath shrub islands and could allow better comparison of microclimate differences. Light intensity was measured using a TES-1339 Light Meter Pro (TES Electrical Electronic, Taiwan). Air relative humidity was calculated from readings of dry and wet bulb temperatures of a psychrometer (Red Star Instrument, Hebei, China), and the dry bulb temperature regarded as air temperature. Moreover, meadow without shrub cover on the cutover was selected as a control check (CK) and the same climate variables were measured at the same time. For each variable, we took at least three readings and used the mean value for the statistical analysis. Light transmission was derived from the ratio of light intensity under the shrub and the CK, and vapor pressure deficit (VPD) was calculated (Jones 1992) from air temperature and relative humidity.

\subsection{Community survey}

Firstly, the projected canopy area for each of the 86 shrubs was regarded as a plot. The plot was divided into four parts (north, south, east and west) in which all herbaceous species, and number and species richness of woody seedlings were recorded. We then set one subplot of $50 \mathrm{~cm} \times 50 \mathrm{~cm}\left(0.25 \mathrm{~m}^{2}\right)$ in the center of each part to investigate coverage of the total herbaceous community, grasses, forbs and litter. We also measured above-ground herbaceous biomass and litter mass by clipping all the herbaceous plants at ground level and collecting the litter, respectively. We regarded the part as one subplot if it was too small to set up a $50 \mathrm{~cm} \times 50 \mathrm{~cm}$ subplot. There were only 14 such subplots (parts) of insufficient sampling size (i.e., $50 \mathrm{~cm} \times 50 \mathrm{~cm}$ ) in 11 small shrub islands. In addition, we established 70 plots of $1 \mathrm{~m} \times 1 \mathrm{~m}$ in the meadow between shrub islands as a control (CK), where all the parameters investigated for shrubs were measured. Samples of plants and litter were transferred into the laboratory, dried at $70^{\circ} \mathrm{C}$ for $12-13 \mathrm{~h}$ and weighed for dry mass. Plant individuals found during the survey were identified in the field when possible or collected for later identification at the herbarium. We calculated the average cover value by four subplots.

\subsection{Soil sample collection and nutrient analysis}

Soil samples $(0-20 \mathrm{~cm}$ layer) under shrub canopies and in the meadow field were collected by soil auger for the determination of nutrient content. From the center of 
each part, three to five sub-samples were combined onsite into a composite sample for one shrub island. All soil samples were air-dried, sieved through a $2-\mathrm{mm}$ mesh and analyzed for soil organic matter (SOM) content by the Walkley-Black method, for total nitrogen content (TN) by the Kjeldahl method, and for total phosphorus content (TP) by Mo-Sb spectrophotometry (Liu 1996).

\subsection{Statistical analyses}

Each microclimate variable for each plot of shrubs was an average of five replicated measurements. Differences in light transmission, air temperature and VPD among Cerasus, Ribes, Rosa and Salix between each shrubarea class and between the three area-classes of one shrub species were tested separately by one-way ANOVA and post hoc LSD tests. For each shrub species, we performed a series of linear regression analyses to determine the effects of shrub area on soil nutrients (SOM, TN and TP), on the herbaceous community (richness and cover of total herbaceous plants, grasses and forbs; and herbaceous plant biomass), on the litter (cover and biomass), and on woody seedling recruitment (richness and number). All the shrub area data was natural log-transformed to achieve normality. Differences in the intercept and slope of linear regression equations for one variable among Ribes, Cerasus, Rosa and Salix were then tested by analysis of covariance (generally known as ANCOVA) and the shrub area, species and the evaluated parameter were considered as the covariate, fixed factor and dependent variables, respectively.

Mann-Whitney non-parametric tests were used to identify differences in TP among Cerasus, Ribes, Rosa, Salix and CK by considering all samples from the same shrub species as replicates, because TP within the canopies did not vary with patch size for each shrub species. A $t$-test was used to determine differences in richness and number of woody seedlings between Ribes and CK, since both did not vary with Ribes shrub area. All statistical analyses were carried out using SPSS 16.0 for Windows (SPSS, Chicago, IL). Data of cover of total herbaceous community, forbs, grasses and litter, and herbaceous biomass were derived from the subplot level; and data of richness of herbaceous plants, grasses and forbs, and richness and number of woody seedlings were derived from plots or shrub islands.

\section{Results}

\subsection{Microclimate}

The light transmission, ground air temperature and VPD decreased with increasing shrub area for all four species (Table 2); however, there were no significant differences in ground air temperature and VPD among Cerasus, Ribes and Rosa, regardless of size. Only Salix islands (compared to the other species) had significantly higher values of air temperature for the medium area class and in VPD for the two larger area classes. Salix islands had significantly higher values for light transmission, in the two smaller area classes, namely small and medium class. In general, there were lower light transmission intensities under Ribes islands compared with the other three species.

\subsection{Soil nutrients}

Both SOM and TN beneath the shrubs were increased significantly with increasing area for all shrub species
Table 2 Difference in light transmisssion, air temperature, and vapor pressure deficit (VPD) for the three area classes among Cerasus, Ribes, Rosa and Salix islands on a high-altitude cutover, eastern Tibetan Plateau. $n=4$ for each area class of each shrub species. Means \pm SE were are shown. Different uppercase letters indicate significant differences among small, medium and large shrubs within the same species, and different lowercase letters indicate significant differences between four shrub species within the same area class (ANOVA, LSD test, $P<0.05$ )

\begin{tabular}{|c|c|c|c|c|c|c|c|c|c|}
\hline & \multicolumn{3}{|c|}{ Light transmission $(\%)$} & \multicolumn{3}{|c|}{ Air temperature $\left({ }^{\circ} \mathrm{C}\right)$} & \multicolumn{3}{|l|}{ VPD $(\mathrm{kPa})$} \\
\hline & Small $^{\mathrm{d}}$ & Medium & Large & Small & Medium & Large & Small & Medium & Large \\
\hline Cerasus & $16.2 \pm 1.0 \mathrm{Ab}$ & $6.2 \pm 0.8 \mathrm{Bb}$ & $3.2 \pm 0.5 \mathrm{Cab}$ & $25.6 \pm 1.5 \mathrm{Aa}$ & $21.22 \pm 0.6 \mathrm{Bb}$ & $19.2 \pm 0.3 \mathrm{Ca}$ & $1.63 \pm 0.17 \mathrm{Aa}$ & $0.93 \pm 0.10 \mathrm{Bab}$ & $0.69 \pm 0.07 \mathrm{Cb}$ \\
\hline Ribes & $15.8 \pm 1.2 \mathrm{Ab}$ & $5.5 \pm 0.7 \mathrm{Bc}$ & $3.1 \pm 0.5 \mathrm{Cb}$ & $24.8 \pm 1.3 \mathrm{Aa}$ & $20.68 \pm 0.5 \mathrm{Bb}$ & $19.2 \pm 0.2 \mathrm{Ca}$ & $1.57 \pm 0.20 \mathrm{Aa}$ & $0.83 \pm 0.08 \mathrm{Bb}$ & $0.66 \pm 0.06 \mathrm{Cb}$ \\
\hline Rosa & $16.0 \pm 0.9 \mathrm{Ab}$ & $6.3 \pm 0.9 \mathrm{Bb}$ & $3.4 \pm 0.4 \mathrm{Cab}$ & $25.5 \pm 1.3 \mathrm{Aa}$ & $20.68 \pm 0.5 \mathrm{Bb}$ & $19.4 \pm 0.3 \mathrm{Ca}$ & $1.62 \pm 0.12 \mathrm{Aa}$ & $0.91 \pm 0.09 \mathrm{Bab}$ & $0.68 \pm 0.07 \mathrm{Cb}$ \\
\hline Salix & $17.7 \pm 1.3 \mathrm{Aa}$ & $7.6 \pm 0.9 \mathrm{Ba}$ & $3.3 \pm 0.5 \mathrm{Ca}$ & $25.9 \pm 1.3 \mathrm{Aa}$ & $22.36 \pm 0.8 \mathrm{Ba}$ & $20.0 \pm 0.6 \mathrm{Ca}$ & $1.68 \pm 0.16 \mathrm{Aa}$ & $1.03 \pm 0.12 \mathrm{Ba}$ & $0.78 \pm 0.10 \mathrm{Ca}$ \\
\hline
\end{tabular}

${ }^{\mathrm{d}}$ Small, 0.5-1.0 $\mathrm{m}^{2}$; Medium, 2.0-3.0 $\mathrm{m}^{2}$; Large, 5.0-7.0 $\mathrm{m}^{2}$; 

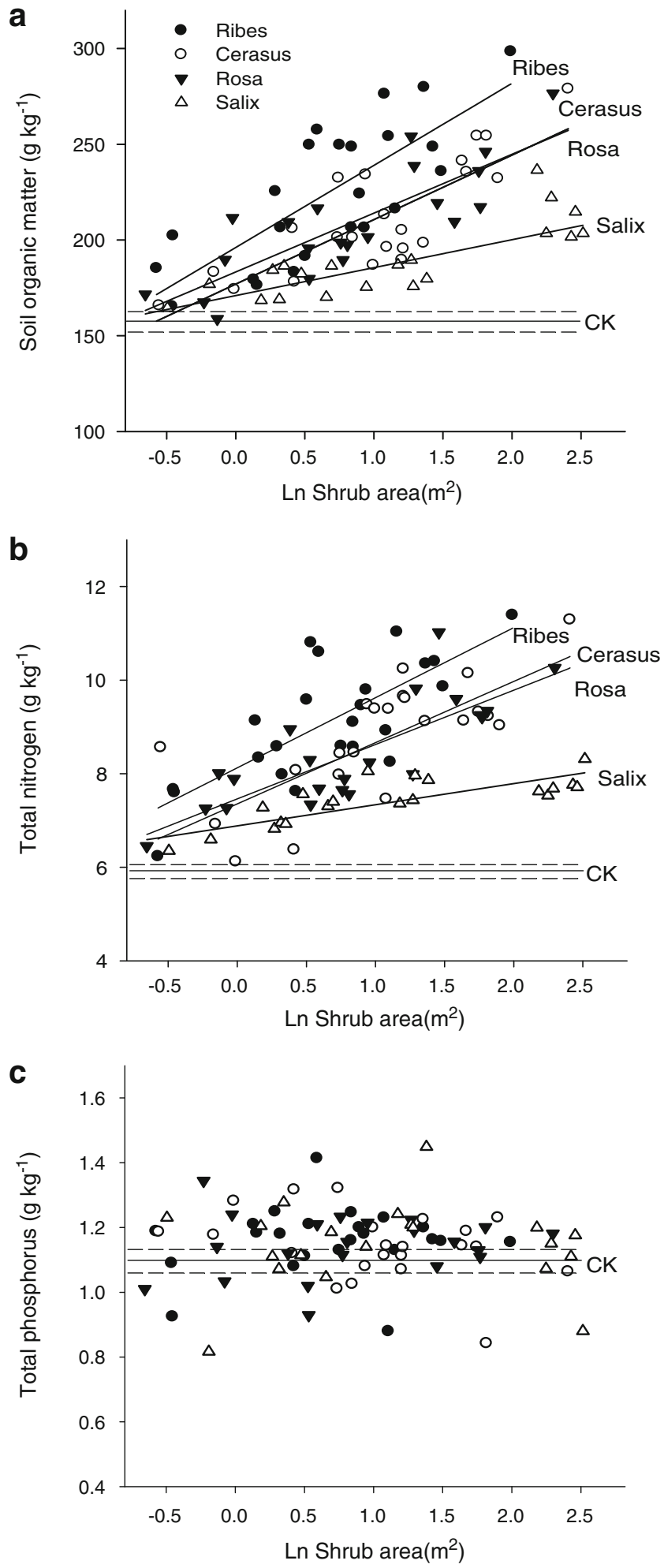

Fig. 1 Contents of a soil organic matter (SOM), b total nitrogen (TN) and $\mathbf{c}$ total phosphorus (TP) in relation to shrub area for Cerasus, Ribes, Rosa and Salix. Regression lines of total phosphorus are not shown because they did not vary with patch size for each shrub species. Parallel dashed lines Mean \pm SE of control (CK) $(n=35)$. Details of the linear equations are provided in Table 3 evaluated (Fig. 1). The intercepts from the regression functions among the four shrub species were significantly different: Ribes $>$ Cerasus $=$ Rosa $>$ Salix $($ Table 3 ). For the small shrub area class, the SOM was highest for Ribes, intermediate for Cerasus and Rosa, and lowest for Salix. The slope values among Ribes, Cerasus and Rosa islands did not differ, but were all higher than that of Salix (Table 3), indicating that SOM and TN accumulation rates under Salix islands were the smallest. TP content, however, did not vary significantly with area for each shrub species; and also no significant differences were seen among Cerasus, Ribes, Rosa, Salix and CK.

\subsection{Herb species richness, cover and biomass}

In total, 124 herb species (13 grasses and 111 forbs) belonging to 89 genera and 32 families were found under all shrub islands investigated. Only 69 herb species (10 grasses and 59 forbs) belonging to 53 genera and 25 families were recorded in the contrast meadow, all of which were also found under the shrub islands. There were 65 species ( 3 grasses and 62 forbs) recorded solely beneath the shrub islands investigated (Appendix 1). For all shrub species, the richness of total herbs, grasses and forbs all gradually increased with shrub area (Fig. 2). There were no significant differences in either the intercepts or slopes of linear regressions between the four shrub species for the richness of total herbaceous plants, grasses and forbs, except that the intercept for grass richness under Salix was lower than for the other species (Table 3).

Total herb cover and biomass decreased markedly with increasing shrub area (Fig. 3). The intercepts of the linear regressions for both the herb cover and biomass differed significantly among shrub species: Salix $>$ Cerasus $\approx$ Rosa $>$ Ribes (Table 3), suggesting that herb cover and biomass were highest under Salix, intermediate under Cerasus and Rosa, and lowest under Ribes in the small shrub area class. The absolute slopes for the total herb cover and biomass for Ribes were significantly higher than those for Cerasus and Rosa, which were in turn higher than for Salix (Table 3). Thus, the rate of decrease in total herb cover and biomass under Ribes was highest, intermediate under Cerasus and Rosa, and lowest under Salix.

Furthermore, grass and forb cover responded differently to increasing shrub area: the former decreased significantly and the latter increased (Fig. 3b,c). The intercepts of the regressions for grass cover under Cerasus, Rosa and Salix did not differ significantly, but were clearly higher than that of Ribes (Table 3 ). Thus the grass cover under Ribes was the lowest for the small area 


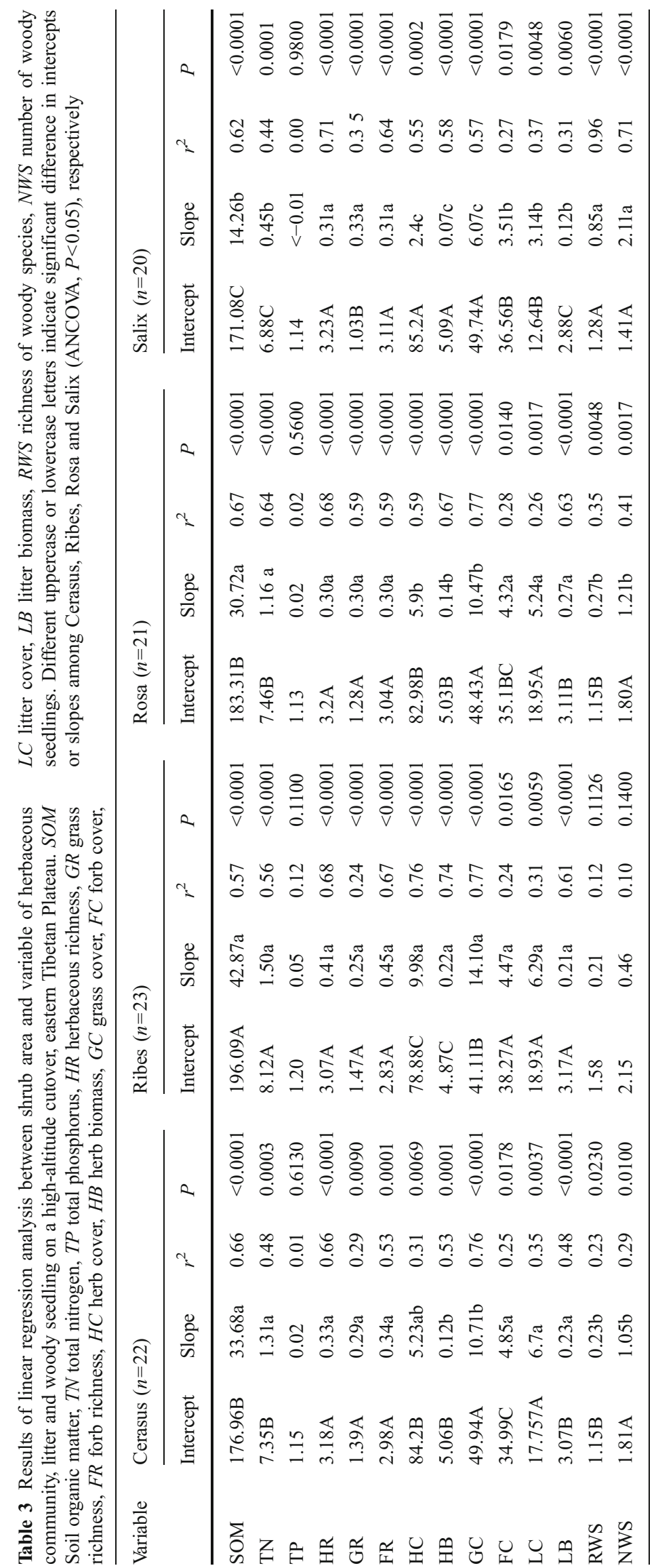



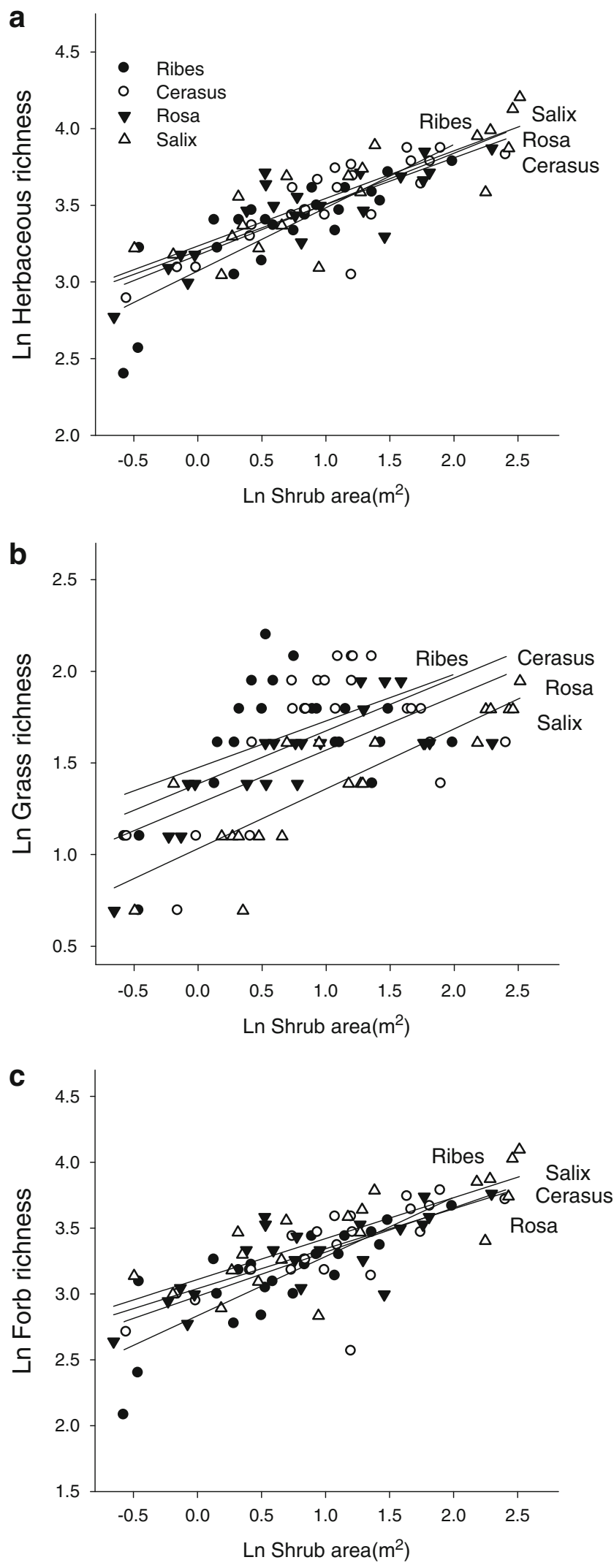

Fig. 2 Species richness of $\mathbf{a}$ herbs, $\mathbf{b}$ grasses and $\mathbf{c}$ forbs in relation to shrub area for Cerasus, Ribes, Rosa and Salix. Details of the linear equations are given in Table 3

class. The species obviously differed in their absolute slopes: Salix $>$ Cerasus $\approx$ Rosa $>$ Ribes (Table 3), demonstrating that the decreased rate of grass cover in relation to shrub canopy area was highest for Ribes, intermediate for Cerasus and Rosa, and lowest for Salix. As for forb cover, the intercept of the function was greatest under Ribes of the four species (Table 3). The slope of the regression for Salix was less than for Cerasus, Ribes and Rosa (Table 3), indicating that the increased rate of forb cover in relation to shrub canopy area under Salix was the lowest.

\subsection{Litter mass and cover}

The litter cover and mass increased gradually with area for all four shrub species (Fig. 4). The intercept and the slope of the linear regression for litter cover under Salix were lower than those under Cerasus, Ribes and Rosa islands (Table 3), suggesting that litter cover under Salix was lowest beneath the small shrub area, and that its accumulation rate with increased shrub area was also lower. For litter mass, the intercepts differed significantly: Ribes $>$ Rosa $\approx$ Cerasus $>$ Salix (Table 3), indicating that Ribes had the highest litter mass and Salix the lowest under the small area of the four species. However, the slope under Salix was lower than for Cerasus, Ribes and Rosa, indicating that the accumulation rate of litter mass with increased shrub area was lowest under Salix.

\subsection{Woody seedling recruitment}

In total, 17 woody plant species seedlings belonging to eight genera and five families were found under the 86 shrub islands investigated. However, only four woody plant species seedlings (Rubus pungens, Rosa omeiensis, Spiraea omeiensis and Salix cupularis) were recorded in the meadow field (Appendix 2). There were 13, 11, 9 and 15 shrub species identified under the Cerasus, Ribes, Rosa and Salix islands, respectively. No tree seedlings were recorded under shrub canopies or in the meadow field. Moreover, 13 out of the 17 woody plant species were vertebrate-dispersed (Appendix 2).

The species richness and number of woody seedlings correlated positively with shrub area for all shrub species except Ribes (Fig. 5; Table 3). The intercept and slope of the linear function for the richness of woody seedlings were higher under Salix islands than Cerasus and Rosa (Table 3). This suggested that woody seedling richness under Salix 

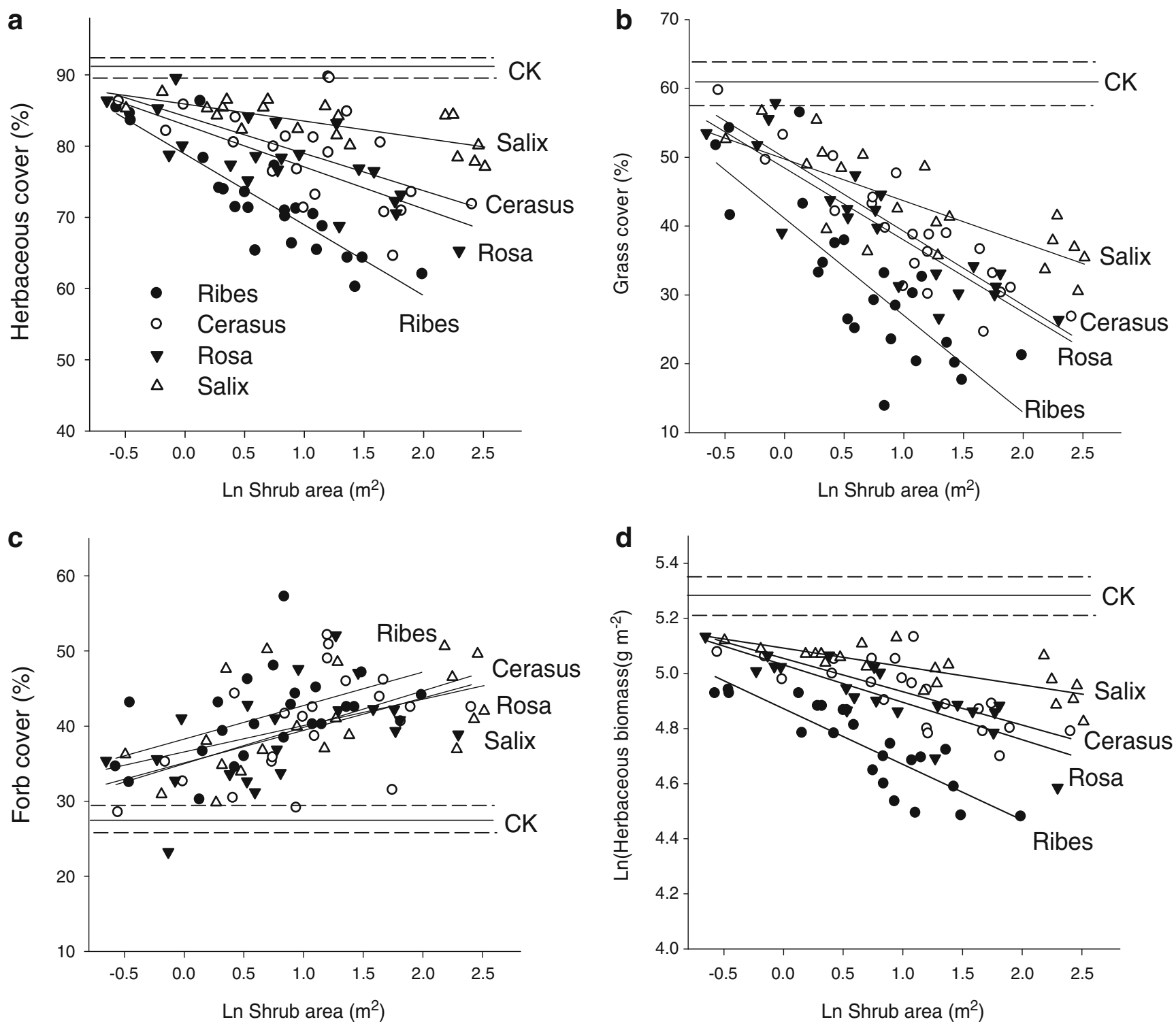

Fig. 3 a Herbaceous cover, $\mathbf{b}$ grass cover, $\mathbf{c}$ forb cover and $\mathbf{d}$ herbaceous biomass in relation to shrub area for Cerasus, Ribes, Rosa and Salix. Parallel dashed lines Mean \pm SE of CK $(n=70)$. Details of the linear equations are given in Table 3

islands was the greatest of the four species for the small area class, and that the accumulation rate was the highest. For the number of woody seedlings, the intercepts showed no difference among the four species (Fig. 5, Table 3); however, the slope for Salix was significantly higher than for Cerasus and Rosa (Table 3). ANCOVA test indicated that all these slopes were noticeably higher than $\mathrm{CK}(P<0.05$, for all cases), suggesting that the rates of increase in the number of woody seedlings in regard to shrub area under these three shrub species were higher than for shrub-free meadow $(\mathrm{CK})$. The richness and number of woody seedlings for Ribes were also greater than in CK (by $t$-tests, $t=7.258$, $P=0.001 ; t=4.331, P=0.017$, respectively).

\section{Discussion}

\subsection{Microhabitat effects}

Our results show clearly that existing shrub significantly reduces light transmission, air temperature and VPD within islands; and that shrub development provided a microclimate gradient according to shrub size (Table 2). These findings in a high-altitude cutover agree with other observations in low-altitude semi-arid and arid regions (Endo et al. 2008). These results can be attributed mainly to variation in foliation levels related to age-dependent size for individual shrub species, since the shrub shading 

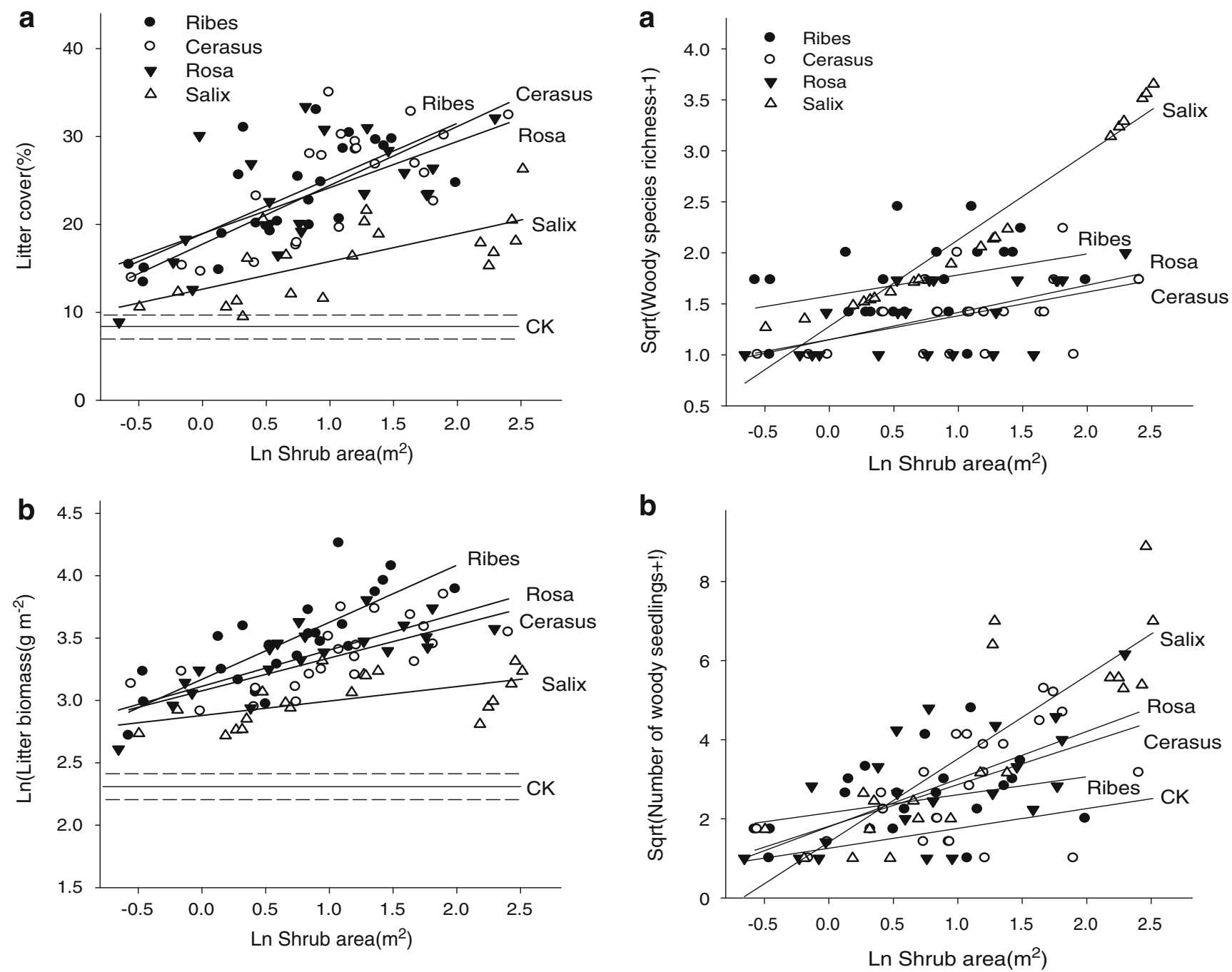

Fig. 4 a Litter cover and $\mathbf{b}$ litter biomass in relation to shrub area for Cerasus, Ribes, Rosa and Salix. Parallel dashed lines Mean $\pm \mathrm{SE}$ of CK $(n=70)$. Details of the linear equations are given in Table 3

level is positively related to foliation level (ReismanBerman 2007) and a shaded microenvironment reduces ground air temperature in summer (Suzán et al. 1996; Shumway 2000). Moreover, the lower temperature and solar radiation would lead to lower VPD (Franco and Nobel 1989) as occurred in the present study (Table 2). We also found a significant difference in microclimate effect among the shrub species (Ribes, Cerasus, Rosa and Salix). The difference in branching angle of crown architecture among shrub species may reasonably explain this. Salix has a higher branch-angle (and low foliation level) and is thus easier for sunlight to penetrate than the other shrubs. Consequently, beneath Salix islands there was higher light transmission, air temperature and VPD than beneath Ribes (Table 2). Microclimate amelioration, especially the reduction in light transmission and VPD
Fig. 5 a Richness of woody seedlings species, and $\mathbf{b}$ number of woody seedlings in relation to shrub area for Cerasus, Ribes, Rosa and Salix. Details of the linear equations are given in Table 3

would be very important in high-altitude regions, since mortality of transplanted spruce seedlings in this region is attributed mainly to desiccation and heat stress (Wang et al. 1995). Therefore, the four investigated shrubs of the high-altitude cutovers could be promising nurse plants for target tree seedling establishment and growth, supporting previous results from spruce seedling reforestation experiment (Wang et al. 1995; Bao 2004).

Shrub islands on the high-altitude cutover significantly improved SOM and TN contents, consistent with results from low-elevation regions (Zhao et al. 2007). Furthermore, SOM and TN contents beneath shrub canopies were significantly and positively related to shrub area, supporting the prediction of Maestre and Cortina (2005). Shrubs can trap plant detritus more effectively, both without and within a canopy, than the 
herb community in a meadow field (Zhao et al. 2007), resulting in litter accumulation under shrub canopies (Fig. 4). Differences in crown architecture may also be responsible for the differences in SOM and TN among shrub species. For instance, Li et al. (2007) found that soil nutrients under Tamarix spp. with their hemispheroidal crowns were significantly higher than those under Haloxylon ammodendron with their Y-shaped crowns, suggesting that Y-shaped crowns were less capable of capturing and maintaining the litter under them than hemispheroidal crowns. Consistent with this, our results showed that there was the highest amount of litter mass accumulation beneath Ribes with its low branching and hemispheroidal crown, medium under Cerasus and Rosa with their medium branching, and the lowest beneath Salix with its high branching (Fig. 4). This resulted in the highest SOM and TN under Ribes, medium under Cerasus and Rosa, and the lowest under Salix (Fig. 1a,b). However, there was no difference in TP content beneath the different shrubs, and between the shrubs and contrasts (Fig. 1c). This is in contrast to the results of Zhao et al. (2007), who found that TP content within a shrub canopy was higher than outside, and that there were significant differences between two species of different canopy shapes. Surprisingly, we found that TP content also did not vary with shrub area for all four shrubs evaluated. Further investigation will be required to explain this result.

\subsection{Herb community effects}

We found that greater herb species richness existed beneath shrubs, and many species were associated exclusively with the shrubs. Furthermore, the richness of the herb species increased significantly and positively with shrub area for all four species examined (Fig. 2). Most notably, we found that grass cover was reduced significantly with increasing shrub size, while forb cover increased (Fig. 3b,c), suggesting a shift from grass- to forb-domination under shrubs as area-size increased. Similar relationships have been found for Mediterranean shrubs such as Ephedra fragillis and Quercus coccifera (Maestre and Cortina 2005). We should note that the different effects of shrub on herb development with the increasing area are correlated closely to shrub species identity, resulting in stronger effects for Salix than other three species (Table 3 ).

The herb community effects can be related closely to microhabitat effects. Throop and Archer (2008) suggested that there are more complex spatial patterns of microclimate under larger shrubs. Such microhabitat heterogeneity could promote differentiation of niches, which increase in number and availability as shrub size increases, leading to establishment of more species (Pugnaire et al. 1996). In present study, shrubs reduced light transmission, so more light-intolerant herb species could occur under larger shrubs with lower light transmission. The effects may also be ascribed to the different responses of forbs and grasses to microhabitat alternation with increasing shrub area according to their adaptation strategies. Forbs generally have higher nitrogen and water requirements than grasses, so the increased availability of these resources may have a greater positive effect on forbs than on grasses, and could enhance individual performance, and result in greater population size and/or biomass production (Turner and Knapp 1996). Moreover, low light conditions, especially in the early growing season, may be less limiting to forbs than grasses, because photosynthesis in forbs saturates with respect to light at a much lower photosynthetic photon flux density (Turner and Knapp 1996). The increase in soil nitrogen and moisture, along with the reduction of available light may thus favor forbs and/or reduce the competitive capability of grasses (Seastedt et al. 1991; Wedin and Tilman 1993). In addition to plant adaptation strategy, the herb community effects of shrubs can be explained according to the indirect facilitation mechanism (Levine 1999; Brooker et al. 2008; Cuesta et al. 2010). The occurrence of shrub species may also convert competition between grasses and forbs into indirect facilitation. Levine (1999) proposed that apparent indirect facilitation may be more likely in assemblages where the different pairs of competitors have significantly different mechanisms to acquire resources. Cuesta et al (2010) provides testimony that the nurse shrub indirectly facilitated seedling growth by reducing the competitive capacity of herbs. Shrubs, forbs and grasses are quite different growth entities, and thus would differ in their pathways to acquire resources; consequently shrubs produced a strong indirect facilitative effect on forbs by suppressing the competing grasses, resulting in a shift from grass- to forb-domination composition with increasing shrub island area.

\subsection{Effects on woody seedling recruitment}

Shrubs facilitate woody seedling recruitment by enhancing the richness of shrub species and increasing the number of shrub seedlings (Fig. 5). Such results can be attributed to the shrub function of the recruitment foci. Shrubs can attract seed-dispersing animals by providing perches, fruits, shade and nesting sites, thus increasing the number and diversity of seeds arriving under their canopies (Duarte et al. 2006). Consequently, the richness and number of seedlings under the shrubs were obviously higher than in the open meadow, and were positively related to shrub area 
for all evaluated shrub species except for Ribes (Fig. 5). Shrubs can also improve the number and richness of woody plant seedlings indirectly by reducing the competition intensity from herbs (Cuesta et al. 2010). In our present work, the decreasing cover and biomass of the herbaceous community meant less resource utilization (e.g., amount of soil nutrients) with increasing shrub area (Fig. 3); therefore, better resource availability probably promoted more richness and a greater number of woody seedlings under larger shrubs (Fig. 5). Kunstler et al (2006) found that the promotion of woody seedling establishment beneath shrubs can also be due to indirect facilitation by shade and competition release from herbs, supporting the above speculation.

Slocum (2001) suggested that woody species with fleshy fruits will probably attract more seed dispersers than those with dry fruits, resulting in favorite woody seedling renewal. However, Salix with dry fruits gave rise to a greater richness and number of woody seedlings than the other three species with fleshy fruits (Fig. 5), indicating that barriers to seedling establishment after seed dispersal were also probably working. Thus, litter may be responsible for the different effects on woody seedling recruitment, as it can inhibit seed germination and seedling establishment of woody species (Xiong and Nilsson 1999). In present work, beneath Ribes presented greater litter cover and biomass but lower richness and number of woody seedlings; conversely, Salix has smaller litter cover and biomass, but higher richness and amount of shrub seedlings (Table 3 ).

Our results also displayed the difference in the facilitation effects from four shrub species for herbaceous species and woody seedlings. The ranking in species effect on the slopes of increasing effects with area was different for the herbaceous species and the woody seedlings (Table 3). Indeed, for herbaceous species, the slope of Salix was lower than that of the three other species (lower effect of Salix), whereas for woody seedlings the slope of Salix was higher (higher effect of Salix) (Table 3). Possible explanations were the shade-tolerance difference for herbaceous species and woody seedlings, and the microhabitat resource difference beneath various shrub islands. Forb species, which account for the major proportion of total herbaceous species, have higher shade-tolerance than woody seedling species, which are composed of early-succession shrubs such as several species from Rubus and Lonicera genera (Appendix 2). The indirect positive effect of the shrubs on both forbs and woody seedlings is due to the competition release of the grasses mentioned above. However, the facilitative effects can be modulated by changing spatiotemporal resources (Soliveres et al. 2010; García-Palacios et al. 2011), and these effects can therefore vary with increasing shade of the shrubs (with area) from Salix to Ribes (Table 3; Figs. 2, 5). We presume there is a threshold of shade above which the effect switches from positive to negative, and that this threshold is earlier for woody seedlings than for forbs, likely because woody seedlings are less shade-tolerant than forbs. Thus, the shade of Salix is at the threshold of this switch for woody seedlings but not for forbs. Although some studies indirectly support this standpoint (Kunstler et al. 2006; Brooker et al. 2008; Cuesta et al. 2010), further research to obtain direct evidence with which to explore this question still is required.

\section{Conclusion}

There were clear effects of shrub islands on microclimate (light transmission, air temperature and VPD), soil nutrients (SOM and TN), herbaceous community (species richness, cover and biomass) and woody seedling recruitment (richness and number) in alpine forest cutovers. These effects were greater for large shrubs than small ones, and also varied among shrubs with different crown architectures, with the result that shrub effects were species- and size-dependent. We also found that differences in species-dependency of the shrub effect for the responses of the herbaceous (grasses and forbs) and woody seedling species, suggested that shrubs also indirectly facilitate forbs and seedling regeneration through competition release of grasses. Thus, the established shrubs can improve hash microhabitats, alter the properties of the communities beneath, facilitate light-tolerant plant diversity development, and accelerate the natural succession process from the herb stage to the shrub stage in patches on cutovers in the high-altitude region of the eastern Tibetan Plateau.

Our results, which will be of use to inform practices in alpine forest restoration and cutover management, suggest that shrub preservation and their utilization as nurse plants for reforestation should be applied to cutover vegetation management prescription in alpine regions. Also, it is better to select large shrubs like Salix as nurse microhabitats for reforestation because they have stronger positive effects on woody seedling nursing.

Acknowledgments This work was funded by a grant from the National Natural Science Foundation of China (No.30570333, 30972350) to W.K.B. We greatly thank D. Yang, Z.H. Se, B. Cheng, C. Wang and X Liu. for their help in the field, and the Key Laboratory of Mountain Ecological Restoration and Biological Resources Utilization of Chinese Academy of Sciences for logistical support. Two anonymous reviewers provided valuable suggestions and comments that improved our explanation of the results. 


\section{Appendix 1}

Table 4 List of herb species identified beneath shrub islands on the clear-cut sites in Rangtang, eastern Tibetan Plateau. A "+" indicates that the species was found in the Cerasus (C. trichostoma), Ribes ( $R$. glaciale), Rosa ( $R$. omeiensis) and Salix (S. sphaeronymphe) or CK (open meadow field)

\begin{tabular}{|c|c|c|c|c|c|c|}
\hline Species & Family & Cerasus island & Ribes island & Rosa Island & Salix Island & CK (Meadow) \\
\hline Aconitum liljestrandii & Ranunculaceae & + & & + & + & \\
\hline Adenophora liliifolioides & Campanulaceae & + & + & + & & \\
\hline Agrostis rupestris & Gramineae & + & + & & & \\
\hline Agrostis perlaxa & Gramineae & + & + & + & + & \\
\hline Ajania tenuifolia & Compositae & + & + & + & + & \\
\hline Ajuga ciliata & Labiatae & + & & + & + & + \\
\hline Ajuga ciliata Bunge var hirta & Labiatae & + & + & & + & \\
\hline Allium prattii & Amaryllidaceae & + & + & + & + & \\
\hline Anaphalis lactea & Compositae & & + & + & + & \\
\hline Anemone cathayensis & Ranunculaceae & + & + & + & + & + \\
\hline Anemone rivularis & Ranunculaceae & + & & + & & + \\
\hline Anemone rivularis & Ranunculaceae & + & + & + & + & + \\
\hline Aquilegia ecalcarata & Ranunculaceae & + & + & & + & + \\
\hline Artemisia globosoides & Compositae & + & + & & + & \\
\hline Artemisia lancea Van & Compositae & & + & + & & + \\
\hline Aster diplostephioides & Compositae & + & + & + & + & + \\
\hline Astragalus membranaceus & Leguminosae & + & + & + & & \\
\hline Athyrium dentigerum & Athyriaceae & + & + & + & & + \\
\hline Bromus epilis Keng & Gramineae & + & + & & + & + \\
\hline Bromus japonicus & Gramineae & + & & + & & \\
\hline Caltha palustris & Ranunculaceae & + & & + & + & \\
\hline Cardamine tangutorum & Brassicaceae & & & + & + & + \\
\hline Carex lehmaii & Cyperaceae & + & + & + & + & + \\
\hline Carex tristachya & Cyperaceae & + & + & + & + & \\
\hline Cerastium fontanum & Caryophyllaceae & + & & + & + & + \\
\hline Chrysosplenium griffithii & Saxifragaceae & + & + & + & & \\
\hline Circaea alpina & Onagraceae & & + & + & + & + \\
\hline Circaeaster agrestis & Ranunculaceae & + & & + & + & + \\
\hline Clematis florida & Ranunculaceae & + & + & & + & \\
\hline Codonopsis pilosula. & Campanulaceae & + & + & + & + & + \\
\hline Corydalis impatiens & Papaveraceae & & + & + & + & + \\
\hline Corydalis linarioides & Papaveraceae & & + & + & + & + \\
\hline Corydalis curviflora & Papaveraceae & + & & & + & + \\
\hline Corydalis edulis & Papaveraceae & + & & + & + & \\
\hline Corydalis laucheana & Papaveraceae & & + & + & & \\
\hline Cystopteris moupinensis & Athyriaceae & + & + & + & + & + \\
\hline Delphinium potaninii & Ranunculaceae & + & & + & + & \\
\hline Deschampsia sp. & Gramineae & + & + & + & + & \\
\hline Deyeuxia arundinacea & Gramineae & & + & + & + & \\
\hline Deyeuxia scabrescens & Gramineae & + & + & + & + & + \\
\hline Doronicum thibetanum & Compositae & + & & & & + \\
\hline Draba borealis & Brassicaceae & + & + & + & + & \\
\hline Dracocephalum heterophyllum & Labiatae & & + & + & & + \\
\hline Elsholtzia ciliata & Labiatae & + & & & & \\
\hline
\end{tabular}


Table 4 (continued)

\begin{tabular}{|c|c|c|c|c|c|c|}
\hline Species & Family & Cerasus island & Ribes island & Rosa Island & Salix Island & CK (Meadow) \\
\hline Elymus tangutorum & Gramineae & + & + & + & + & + \\
\hline Elymus nutans & Gramineae & + & + & & + & + \\
\hline Epilobium angustifolium & Onagraceae & + & + & + & + & + \\
\hline Epilobium palustre & Onagraceae & & & + & + & + \\
\hline Epilobium tibetanum & Onagraceae & + & + & + & + & \\
\hline Equisetum arvense & Equisetaceae & + & + & + & + & \\
\hline Euphrasia Tenore & Scrophulariaceae & + & + & + & + & \\
\hline Festuca ovina & Gramineae & + & & + & + & \\
\hline Fragaria orientalis & Rosaceae & + & & & + & + \\
\hline Galium paradoxum & Rubiaceae & + & + & + & + & + \\
\hline Galium trifidum & Rubiaceae & + & & + & + & \\
\hline Gentiana syringea & Gentianaceae & + & + & + & + & + \\
\hline Gentianopsis paludosa & Gentianaceae & & + & + & + & + \\
\hline Geranium pylzowianum & Geraniaceae & + & + & + & + & + \\
\hline Geum aleppicum & Rosaceae & + & & + & + & \\
\hline Halenia elliptica & Gentianaceae & + & & + & + & \\
\hline Heteropappus altaicus & Compositae & + & + & + & + & \\
\hline Impatiens noli-tangere & Balsaminaceae & & + & + & + & \\
\hline Inula linariifolia & Compositae & & + & + & + & + \\
\hline Inula japonica & Compositae & + & + & + & + & + \\
\hline Juncus allioides & Juncaceae & + & + & + & + & + \\
\hline Juncus potaninii & Juncaceae & + & + & + & + & \\
\hline Leontopodium haplophylloides & Compositae & + & & + & + & + \\
\hline Ligularia sagitta & Compositae & + & & + & + & + \\
\hline Melica przewalskyi & Gramineae & + & + & & + & \\
\hline Microula younghusbandii & Boraginaceae & & + & + & + & \\
\hline Microula trichocarpa & Boraginaceae & + & + & + & + & \\
\hline Microula turbinata & Boraginaceae & + & + & + & + & \\
\hline Notholirion bulbuliferum & Liliaceae & + & + & + & + & + \\
\hline Notopterygium incisum & Umbelliferae & + & + & + & + & \\
\hline Parasenecio deltophyllus & Compositae & + & + & + & & \\
\hline Pedicularis chenocephala & Scrophulariaceae & + & + & + & + & \\
\hline Pedicularis kansuensis & Scrophulariaceae & + & + & + & & + \\
\hline Pedicularis rudis & Scrophulariaceae & + & + & + & + & \\
\hline Pilea racemosa & Urticaceae & + & & & & \\
\hline Plantago major. & Plantaginaceae & & & & & \\
\hline Роа аппиа & Gramineae & + & + & + & + & + \\
\hline Poa elanata & Gramineae & + & & + & + & + \\
\hline Poa malaca & Gramineae & + & + & + & + & + \\
\hline Polygonatum verticillatum & Liliaceae & + & + & + & + & \\
\hline Polygonum polystachyum & Polygonaceae & + & + & + & & \\
\hline Polygonum sparsipilosum & Polygonaceae & + & + & + & + & \\
\hline Polygonum viviparum & Polygonaceae & + & + & + & + & + \\
\hline Polystichum shensiense & Dryopteridaceae & + & + & & & + \\
\hline Primula polyneura & Primulaceae & + & + & + & + & + \\
\hline Pseudostellaria sylvatica & Caryophyllaceae & & + & + & + & + \\
\hline Pternopetalum longicaule & Umbelliferae & & + & + & + & \\
\hline Ranunculus tanguticus & Ranunculaceae & + & & + & & \\
\hline Rheum palmatum & Polygonaceae & & & + & + & \\
\hline
\end{tabular}


Table 4 (continued)

\begin{tabular}{|c|c|c|c|c|c|c|}
\hline Species & Family & Cerasus island & Ribes island & Rosa Island & Salix Island & CK (Meadow) \\
\hline Rhodiola kirilowii & Crassulaceae & + & + & + & + & + \\
\hline Rhodiola quadrifida & Crassulaceae & & + & + & & + \\
\hline Rhodiola eurycarpa & Crassulaceae & & + & + & + & \\
\hline Roegneria parvigluma & Gramineae & + & + & + & & \\
\hline Roegneria kamoji & Gramineae & + & + & + & + & \\
\hline Rumex crispus & Polygonaceae & & + & + & + & \\
\hline Salvia prattii & Labiatae & + & + & + & + & \\
\hline Sanicula chinensis & Umbelliferae & + & + & & + & \\
\hline Saussurea cana & Compositae & & + & + & + & + \\
\hline Saussurea japonica & Compositae & + & + & + & & + \\
\hline Saxifraga egregia & Saxifragaceae & & + & + & & + \\
\hline Scutellaria baicalensis & Labiatae & + & & + & + & \\
\hline Sibbaldia tenuis & Rosaceae & & + & + & + & + \\
\hline Sinocarum coloratum & Umbelliferae & + & + & + & + & \\
\hline Souliea vaginata & Ranunculaceae & & + & + & & + \\
\hline Stipa penicillata & Gramineae & & + & + & + & + \\
\hline Taraxacum maurocarpum & Compositae & + & + & + & + & \\
\hline Thalictrum przewalskiii. & Ranunculaceae & + & & & + & + \\
\hline Trigonotis peduncularis & Boraginaceae & + & + & + & & + \\
\hline Trigonotis tibetica & Boraginaceae & + & + & + & + & \\
\hline Trisetum clarkei & Gramineae & + & + & + & + & + \\
\hline Urtica fissa & Urticaceae & + & + & + & + & \\
\hline Valeriana officinalis & Valerianaceae & + & + & + & + & \\
\hline Valeriana tangutica & Valerianaceae & + & & + & + & \\
\hline Veronica eriogyne & Scrophulariaceae & + & + & + & + & + \\
\hline Veronica szechuanica & Scrophulariaceae & & + & + & + & + \\
\hline Veronica didyma & Scrophulariaceae & + & + & + & & + \\
\hline Veronica rockii & Scrophulariaceae & + & + & + & & + \\
\hline Viola biflora & Violaceae & + & + & + & + & \\
\hline Viola rockiana & Violaceae & + & + & + & + & + \\
\hline
\end{tabular}

\section{Appendix 2}

Table 5 Species list of woody seedlings identified beneath shrub islands on clear-cut sites in the eastern Tibetan Plateau. A "+" indicates that the species was found in Cerasus (Cerasus trichostoma),
Ribes (Ribes glaciale), Rosa (Rosa omeiensis) or Salix (Salix sphaeronymphe) or CK (open meadow field)

\begin{tabular}{|c|c|c|c|c|c|}
\hline Species & Family & Cerasus & Ribes & Rosa & Salix \\
\hline Berberis diaphana ${ }^{\mathrm{a}}$ & Berberidaceae & + & + & & \\
\hline Cerasus trichostoma & Rosaceae & + & & & + \\
\hline Lonicera hemsleyana & Caprifoliaceae & + & + & + & + \\
\hline Lonicera hispida & Caprifoliaceae & + & + & + & + \\
\hline Lonicera webbiana & Caprifoliaceae & & + & + & \\
\hline Potentilla glabra & Rosaceae & + & + & + & + \\
\hline Ribes glaciale & Saxifragaceae & + & + & + & + \\
\hline Ribes meyeri & Saxifragaceae & + & + & & + \\
\hline
\end{tabular}


Table 5 (continued)

\begin{tabular}{|c|c|c|c|c|c|c|}
\hline Species & Family & Cerasus & Ribes & Rosa & Salix & $\mathrm{CK}$ \\
\hline Ribes tenue & Saxifragaceae & & + & + & + & \\
\hline Ribes alpestre & Saxifragaceae & + & & & + & \\
\hline Ribes himalense & Saxifragaceae & + & & & + & + \\
\hline Rosa omeiensis & Rosaceae & + & + & + & + & \\
\hline Rosa sericea & Rosaceae & + & & & + & \\
\hline Rubus lutescens & Rosaceae & & & & + & + \\
\hline Rubus pungens & Rosaceae & + & + & + & + & + \\
\hline Salix sphaeronymphe & Salicaceae & & & & + & + \\
\hline Spiraea omeiensis $^{\mathrm{a}}$ & Rosaceae & + & + & + & + & \\
\hline
\end{tabular}

${ }^{\text {a }}$ Not vetebrate-dispersed

\section{References}

Bao WK (2004) Environmental degradation on forest logging blank, vegetation restoration, and management in Tibetan Plateau. In: Zheng D, Yao TD (eds) Uplifting of Tibetan Plateau with its environmental effects. Science, Beijing, pp 537-542

Brooker RW, Maestre FT, Callaway RM, Lortie CL, Cavieres LA, Kunstler G, Liancourt P, Tielbörger K, Travis JMJ, Anthelme F, Armas C, Coll L, Corcket E, Delzon S, Forey E, Kikvidze Z, Olofsson J, Pugnaire F, Quiroz CL, Saccone P, Schiffers K, Seifan M, Touzard B, Michalet R (2008) Facilitation in plant communities: the past, the present, and the future. J Ecol 96:18-34

Cuesta B, Villar-Salvador P, Puértolas J, Benayas JM, Michalet R (2010) Facilitation of Quercus ilex in Mediterranean shrubland is explained by both direct and indirect interactions mediated by herbs. J Ecol 98:687-696

Dona AJ, Galen C (2007) Nurse effects of alpine willows (Salix) enhance over-winter survival at the upper range limit of fireweed Chamerion angustifolium. Arc Antarct Alp Res 39:57-64

Duarte LDS, Dos-Santos MMG, Hartz SM, Pillar VD (2006) Role of nurse plants in Araucaria forest expansion over grassland in south Brazil. Austr Ecol 31:520-528

Endo M, Yamamura Y, Tanaka A, Nakano T, Yasuda T (2008) Nurseplant effects of a dwarf shrub on the establishment of tree seedlings in a volcanic desert on Mt, Fuji, central Japan. Arct Antarct Alp Res 40:335-342

Franco AC, Nobel PS (1989) Effect of nurse plants on the microhabitat and growth of cacti. J Ecol 77:870-886

García-Palacios P, Maestre FT, Gallardo A (2011) Soil nutrient heterogeneity modulates ecosystem responses to changes in the identity and richness of plant functional groups. J Ecol 99:551-562

Garner W, Steinberger Y (1989) A proposed mechanism for the formation of fertile in the desert ecosystem. J Arid Environ 16:257-262

Jones HG (1992) Plants and microclimate, a quantitative approach to environmental plant physiology, 2nd edn. Cambridge University Press, Cambridge, UK

Körner C (2003) Alpine plant life - function plant ecology of high moutain ecosystems. Springer, Heidelberg

Kunstler G, Curt T, Bouchaud M, Lepart J (2006) Indirect facilitation and competition in tree species colonization of subMediterranean grasslands. J Veg Sci 17:379-388

Levine JM (1999) Indirect facilitation: evidence and predictions from a riparian community. Ecology 80:1762-1769

Li J, Zhao C, Zhu H, Li Y, Wang F (2007) Effect of plant species on shrub fertile isalnd at an oasis-desert ecotone in the South Junggar Basin, China. J Arid Environ 71:350-361
Liu GS (1996) Soil physical and chemical analys and description of soil profiles. Standards Press of China, Beijing, China

Maestre FT, Cortina J (2005) Remnant shrubs in Mediterranean semiarid steppes: effects of shrub size, abiotic factors and species identity on understorey richness and occurrence. Acta Oecol 27:161-169

Mattson KDM, Putz FE (2008) Sand pine (Pinus clausa) seedling distribution and biomechanics in relation to microsite conditions and proximity to potential nurse plants. For Ecol Manag 255:3778-3782

Pugnaire FI, Haase P, Puigdefábregas J, Cueto M, Clark SC, Incoll LD (1996) Facilitation and succession under the canopy of a leguminous shrub, Retama sphaerocarpa, in a semi-arid environment in south-east Spain. Oikos 76:455-464

Reisman-Berman O (2007) Age-related change in canopy traits shifts conspecific facilitation to interference in a semi-arid shrubland. Ecography 30:459-470

Seastedt TR, Briggs JM, Gibson DJ (1991) Controls of nitrogen limitation in tallgrass prairie. Oecologia 87:72-79

Shumway SW (2000) Facilitative effects of a sand dune shrub on species growing beneath the shrub canopy. Oecologia 124:138-148

Slocum MG (2001) How tree species differ as recruitment foci in a tropical pasture. Ecology 82:2547-2559

Soliveres S, DeSoto L, Maestre FT, Olano JM (2010) Spatio-temporal heterogeneity in abiotic factors can modulate multiple ontogenetic shifts between competition and facilitation. Persp Plant Ecol Evol Syst 12:227-234

Suzán H, Nabhan GP, Patten DT (1996) The importance of Olneya tesota as a nurse plant in the Sonoran Desert. J Veg Sci 7:635-644

Throop HL, Archer SR (2008) Shrub (Prosopis velutina) encroachment in a semidesert grassland: spatial-temporal changes in soil organic carbon and nitrogen pools. Global Change Biol 14:2420-2431

Turner CL, Knapp AK (1996) Responses of a C4 grass and three C3 forbs to variation in nitrogen and light in tallgrass prairie. Ecology 77:1738-1749

Wang JX, Xu JD, Hou GW, Liu JB, Pu JT, Shi LX, Liao GY (1995) Ecology and regeneration of cut-overs in high-altitude and plateau region of the upper reach of Yangtze river. Chinese Publication House of Forestry, Beijing

Wedin D, Tilman D (1993) Competition among grasses along a nitrogen gradient-initial conditions and mechansims of competition. Ecol Monogr 63:199-229

Xiong SJ, Nilsson C (1999) The effects of plant litter on vegetation: a meta-analysis. J Ecol 87:984-994

Zhao HL, Zhou RL, Su YZ, Zhang H, Zhao LY, Drake S (2007) Shrub facilitation of desert land restoration in the Horqin sand land of Inner Mongolia. Ecol Eng 31:1-8 